G. Capogna MD*, D. Celleno MD*,

P. Costantino $\mathrm{MD}^{*}$, F. Muratori $\mathrm{MD}^{*}$, M. Sebastiani MD*, M. Baldassini MD $\dagger$

\title{
Alkalinization improves the quality of lidocaine- fentanyl epidural anaesthesia for Caesarean section
}

This double-blind randomized study of 116 healthy women was undertaken to evaluate whether alkalinization potentiated the analgesic effects of epidural fentanyl-lidocaine for elective Caesarean section. After a test-dose of $3 \mathrm{ml}$, lidocaine $2 \%$ with adrenaline 1:200,000, all patients received $100 \mu \mathrm{g}$, fentanyl in $5 \mathrm{ml}$ saline and they were then divided into two groups, to receive incremental doses of $5 \mathrm{ml}$ lidocaine $2 \%$ with adrenaline 1:200,000 with or without $0.1 \mathrm{mEq} \cdot \mathrm{ml}^{-1}$ sodium bicarbonate, to obtain anaesthesia to $T_{4}$. The addition of bicarbonate to lidocaine resulted in a mean (SD) $\mathrm{pH}$ increase from $6.58(0.01)$ to $7.14(0.02)$ and in a mean $\mathrm{PCO}_{2}$ increase from $3.8(0.8)$ to 345.1 (5.9) $\mathrm{mmHg}$. Onset of sensory analgesia to the $S_{l}$ segment as well as the interval between the block and the delivery of the baby were shorter in the bicarbonate group (respectively 15.4 (6.9) vs 18.9 (4.8) min and 28.9 (9.5) versus 33.9 (11.8) min; $P<0.01$ and 0.05). No differences were noted in the onset to $T_{4}$ or in the degree of motor block. The percentage of patients experiencing pain during surgery and requiring intravenous analgesics was higher in the group which did not receive bicarbonate (3\% vs $16 \% ; P<0.05$ ). There were no differences in intraoperative maternal side-effects, neonatal outcome or in maternal venous and umbilical venous and arterial lidocaine concentrations between the groups. The concentrations of fentanyl in maternal plasma, umbilical artery, and the umbilical artery to maternal vein ratio were greater in the al-

\section{Key words}

ANAESTHESIA: obstetric;

ANAESTHETIC TECHNIQUES: regional, epidural; ANAESTHETICS: local, lidocaine.

From the Departments of Anaesthesiology* and Clinical Biochemistry $\dagger$, Fatebenefratelli General Hospital, Isola

Tiberina, 00186 Rome, Italy.

Presented, in part, at the 10th World Congress of

Anaesthesiologists, The Hague, The Netherlands, 1992.

Address correspondence to: Dr. G. Capogna, via M. Saveria Sanzi 21, 00151 Rome, Italy.

Accepted for publication 23rd January, 1993. kalinized group $(P<0.001)$. In conclusion, alkalinization improves the quality and reliability of epidural anaesthesia provided with fentanyl and lidocaine for Caesarean section in healthy mothers.

Cette étude randomisée à double inconnue est réalisée chez 116 patientes en bonne santé pour évaluer si lalcalinisation potentialise les effets analgésiques de l'association fentanyllidocaïne en épidurale pour la césarienne programmée. Après une dose-test de lidocaïne 2\% adrénalinée à 1:200,000 $3 \mathrm{ml}$, toutes les patientes reçoivent fentanyl $100 \mu \mathrm{g}$ dans du soluté physioloque et sont divisées en deux groupe. Elles reçoivent des doses progressives de lidocaïne $2 \%$ adrénalinée à 1:200,000 $5 \mathrm{ml}$ avec ou sans bicarbonate de sodium $0,1 \mathrm{mEq} \cdot \mathrm{ml}^{-1}$ jusquà ce que le niveau $T_{4}$ soit atteint. L'addition de bicarbonate à la lidocaïne augmente en moyenne ( $(S D)$ le $p H$ de $6,58(0,01)$ à $7,14(0,02)$ et la $\mathrm{PCO}_{2}$ en moyenne de $3,8(0,8)$ à $345,1(5,9)$ $\mathrm{mmHg}$. Le début de l'anesthésie sensorielle mesurée au niveau $S_{1}$ et lintervalle entre linitiation du bloc et la naissance sont plus courts pour le groupe bicarbonate (respectivement 15,4 $(6,9)$ min vs $18,9(4,8)$ min et $28,9(9,5)$ vs $33,9(11,8) \mathrm{min}$; $P<0,01$ et 0,05$)$. On ne note pas de différence quant au début de l'analgésie à $T_{4}$ ou au degré du bloc moteur. Le pourcentage de patientes qui ressentent de la douleur pendant la chirurgie et qui reşoivent un analgésique iv est plus élevé dans le groupe qui ne reçoit pas de bicarbonate (3\% vs 16\%; $P<$ $0,05)$. On ne trouve pas de différence entre groupes pour l'incidence des effets secondaires, le pronostic néo-natal ou les concentrations plasmatiques ombilicales artérielles et veineuses. La concentration plasmatique de fentanyl dans l'artèreombilicale est plus élevée dans le groupe bicarbonate ainsi que le rapport veineux ombilical-artère maternelle $(P<0,001)$. En conclusion, l'alcalinisation améliore la qualité et la fiabilité de l'anesthésie épidurale produite par le fentanyl et la lidocaïne pour la césarienne de patientes en bonne santé.

Pain or discomfort during Caesarean section during epidural anaesthesia occur with different frequency, depending on the cause. ${ }^{1,2}$ Severe visceral pain occurs unex- 
pectedly, despite an adequate sensory level of analgesia. Visceral pain is common when peritoneal structures are stimulated or when uterine exteriorization is performed.

The addition of fentanyl to the local anaesthetic has been demonstrated to improve the intraoperative quality of analgesia. ${ }^{3-6}$ Also, alkalinization of local anaesthetic has been reported to improve intraoperative analyesia during Caesarean section. ${ }^{7,8}$ There is some laboratory evidence that the addition of bicarbonate may improve the action of opioids. ${ }^{9}$ This double-blind randomized study was undertaken to evaluate whether alkalinization of the local anaesthetic solution potentiated the analgesic effects of epidural fentanyl-lidocaine mixtures for elective Caesarean section.

\section{Methods}

One hundred and sixteen healthy women with a single fetus, at term (gestational age 38-42 wk), undergoing elective Caesarean section, were involved in this study. Hospital Ethics Committee approval and informed consent were obtained. The patients received $1000-1500 \mathrm{ml}$ Ringer's lactate solution $\dot{i} v$ before the epidural block. An epidural catheter was inserted in the mid-lumbar region with the patient in the sitting position, using a 16 gauge Tuohy needle. After $3 \mathrm{ml}$ lidocaine $2 \%$ with adrenaline 1:200,000 as a test-dose, patients received $100 \mu \mathrm{g}$ fentanyl in $5 \mathrm{ml}$ saline. The patients were then placed supine and divided into two groups, to receive incremental doses (every two to three minutes) of $5 \mathrm{ml}$ lidocaine $2 \%$ with adrenaline $1: 200,000$ with or without $0.1 \mathrm{mEq} \cdot \mathrm{ml}^{-1}$ of sodium bicarbonate, to obtain surgical anaesthesia to $T_{4}$. If a $T_{4}$ sensory level was not achieved, the patient was excluded from the study. Adrenaline was added freshly to the plain preservative-free solution of lidocaine. Bicarbonate (or saline, as control) was also added just before administering the local anaesthetic solution. Repeated measures of $\mathrm{pH}$ and $\mathrm{PCO}_{2}$ of the solution were made, for each patient, by an ABL Apparatus (Radiometer, Copenhagen), immediately before and after alkalinization, as well as immediately before administration of the solution. The mother and the investigator were blinded to the addition of bicarbonate.

All patients were maintained with left uterine displacement and were given supplementary oxygen until delivery. Pulse oximetry was displayed continuously and arterial pressure and heart rate were recorded every three minutes until the completion of the block and then every five minutes together with the progress of the block. Hypotension, defined as systolic arterial pressure of less than $100 \mathrm{mmHg}$ or a reduction of more than $30 \%$ from baseline, was treated with a bolus of ephedrine $10 \mathrm{mg} i v$, repeated as necessary. Sensory block was assessed by the loss of sensation of pinprick. Motor block was assessed by Bromage's criteria as follows: $0 \%=$ no motor block (free movement of legs and feet); 33\% = partial motor block (patient just able to flex the knees with free movement of the feet); $66 \%=$ motor block almost complete (patient unable to flex the knees but with free movement of the feet) and $100 \%=$ complete motor block (patient unable to move legs or feet). The onset of epidural block, assessed by sensory loss to pinprick, was defined as the interval from initial epidural injection (test dose) to the establishment of bilateral sensory analgesia to $T_{4}$. Onset time to $S_{1}$ was also evaluated. Intraoperatively, analgesia during surgery was rated, by the anaesthetist, as $3=$ excellent, no pain, 2 = good, minimal discomfort during surgery that did not require any additional treatment, $1=$ fair, moderate or persisting pain requiring additional analgesics, $0=$ failed (conversion to general anaesthesia). Any sensation of pressure, heaviness, tightness that did not require any treatment was defined as "discomfort." Surgical pain was measured, using the above scale, at the time of incision, during bladder retraction, at neonatal delivery, during exteriorization of the uterus and during peritoneal closure. Any spontaneous complaint of the patients concerning pain, discomfort, or the presence of any side effect was recorded. Any pain during the procedure was treated by inhalation of a 50:50 mixture of oxygen and nitrous oxide and, if necessary, with $i v$ analgesics (fentanyl $50-100 \mu \mathrm{g}$ ) or sedatives (diazepam 5-10 mg). All patients were observed for intraoperative side effects, such as hypotension (before and after the delivery), nausea, vomiting, pruritus, and sedation. The interval from the first epidural injection to delivery (I-D interval), uterine incision to delivery (U-D interval) and the duration of surgery were noted. The total dose of lidocaine necessary to achieve the $T_{4}$ sensory level, including the test dose, was also recorded.

In 20 patients for each group, maternal venous blood samples were taken from the non-infusion arm before the block, five minutes after the block and then every ten minutes from the time at which administration of local anaesthetic solution was started until the end of operation. Umbilical arterial and maternal and umbilical venous blood samples were taken immediately after delivery. After centrifugation and plasma separation, all samples were frozen at $-30^{\circ} \mathrm{C}$ and stored until assayed. Determination of lidocaine and fentanyl concentrations was performed by FPIA technique (Fluorescence Particle Immuno Assay, Abbott Lab, IL, USA). This technique has a sensitivity for lidocaine/fentanyl respectively of $\mathbf{0 . 1 0}$ $\mu \mathrm{g} \cdot \mathrm{ml}^{-1}$ and $20 \mathrm{ng} \cdot \mathrm{ml}^{-1}$ and a variability less than $5 \%$.

Neonatal assessment included Apgar scoring at one and five minutes, umbilical venous and arterial blood gas analyses and neurobehavioural examinations (Neurologic and Adaptive Capacity Score) at 1, 4 and $24 \mathrm{hr} .{ }^{10}$ 
Neonatal evaluations were performed by an anaesthetist blinded to maternal treatment.

The patients were questioned about their satisfaction during the surgical procedure immediately after the surgery and the following day, using a visual analogue scale $(0=$ not satisfied; $10=$ fully satisfied $)$.

Statistical analysis was performed using Student's t test, Mann Whitney $U$ test and chi square test where appropriate. A $P$ value $<0.05$ was considered to be significant.

\section{Results}

At the end of the study 62 patients were included in the alkalinized group and 50 in the plain group. Four patients in the plain group were excluded from the study because of failure to achieve $T_{4}$ block.

The patients' demographic data did not differ (Table 1). The addition of bicarbonate to lidocaine resulted in a mean (SD) $\mathrm{pH}$ increase from $6.575(0.01)$ to $7.138(0.02)$ and in a mean $\mathrm{PCO}_{2}$ increase from $3.8(0.8)$ to 345.1 (5.9) $\mathrm{mmHg}$. No precipitate was observed in any preparation. The solutions remained stable and at the same $\mathrm{pH}$ and $\mathrm{PCO}_{2}$ values for $20 \mathrm{~min}$.

The mean dose of lidocaine required to achieve $T_{4}$ block did not differ between the groups (Table II). Onset of sensory analgesia to the $S_{1}$ segment as well as the time interval between the block and the delivery of the baby were shorter in the bicarbonate group (Table II). No differences were noted in the degree of motor block (Table II). None of the patients required general anaesthesia. In all cases the obstetrician exteriorized the uterus during surgery. The mean duration of the surgery was comparable between the groups (Table II). The number of patients experiencing pain during surgery and requiring intravenous analgesics was higher in the group which did not receive bicarbonate $(P<0.05)$ (Table III). The incidence of maternal intraoperative side-effects did not differ between the groups (Table IV). In all cases predelivery hypotension was corrected promptly and did not last more than one minute. No differences were noted concerning the neonatal characteristics and outcome. All neonates had an Apgar score of 8 or more at one minute and a neurological and adaptive score more than 35 at 1,4 and $24 \mathrm{hr}$. All the umbilical blood gas and $\mathrm{pH}$ values were in normal range.

Maternal mean plasma concentrations of lidocaine did not differ between the two groups at any sampling time (Figure 1). The groups were also similar with respect to maternal venous and umbilical venous and arterial lidocaine concentrations as well as to umbilical venous to maternal venous and umbilical arterial to umbilical venous lidocaine concentration ratios. The peak plasma lidocaine concentration:dose ratio were comparable be-
TABLE I Demographic data

\begin{tabular}{lcc}
\hline & Alkalinized group & Plain group \\
\hline Age $(\mathrm{yr})$ & $30.5(2.8)$ & $32.1(6.0)$ \\
Weight $(\mathrm{kg})$ & $68.4(8.9)$ & $74.3(11.2)$ \\
Height $(\mathrm{cm})$ & $165.9(6.9)$ & $170.1(6.9)$ \\
GA (wk) & $39.1(1.2)$ & $39.6(0.4)$ \\
Neonatal weight $(\mathrm{g})$ & $3328.6(476.5)$ & $3417.9(551.8)$ \\
\hline
\end{tabular}

Values are presented as mean (SD); GA: gestational age.

TABLE Il Data concerning the block and the surgery

\begin{tabular}{lccc}
\hline & $\begin{array}{l}\text { Alkalinized } \\
\text { group }\end{array}$ & $\begin{array}{l}\text { Plain } \\
\text { group }\end{array}$ & $P$ \\
\hline Lidocaine (mg) & $401.1(82.6)$ & $380.8(56.4)$ & \\
Onset to $\mathrm{T}_{4}(\mathrm{~min})$ & $16.7(7.6)$ & $17.8(5.5)$ & \\
Onset to $\mathrm{S}_{1}(\mathrm{~min})$ & $15.4(6.9)$ & $18.9(4.8)$ & $<0.01$ \\
l-D interval (min) & $28.9(9.5)$ & $33.9(11.8)$ & $<0.05$ \\
U-D interval (sec) & $61.3(31.9)$ & $66.2(42.3)$ & \\
Duration of surgery (min) & $49.4(15.9)$ & $51.6(21.8)$ & \\
Motor block & & & \\
$-0 \%$ & $2(3 \%)$ & $2(4 \%)$ & \\
$-33 \%$ & $21(33 \%)$ & $23(46 \%)$ & \\
$-66 \%$ & $31(50 \%)$ & $19(38 \%)$ & \\
$-100 \%$ & $8(12 \%)$ & $6(12 \%)$ & \\
\hline
\end{tabular}

Values are presented as mean (SD); I-D: time interval between epidural block and delivery; U-D: uterine incision to delivery time interval; lidocaine: mean dose of lidocaine to achieve $T_{4}$ block; motor block: Bromage's Criteria (number of patients and \%).

TABLE III Intraoperative analgesia (number of patients and percentage)

\begin{tabular}{lccl}
\hline & $\begin{array}{l}\text { Alkalinized } \\
\text { group }\end{array}$ & Plain group & $P$ \\
\hline No pain, excellent analgesia & $54(87 \%)$ & $36(72 \%)$ & NS \\
Discomfort, no treatment & $6(11 \%)$ & $6(12 \%)$ & NS \\
Pain requiring treatment & $2(3 \%)$ & $8(16 \%)$ & $<0.05$ \\
\hline
\end{tabular}

TABLE IV Maternal intraoperative side effects (number of patients and percentage)

\begin{tabular}{lcc}
\hline & Alkalinized group & Plain group \\
\hline Pre-delivery hypotension & $30(48 \%)$ & $23(46 \%)$ \\
Shivering & $2(3 \%)$ & $5(10 \%)$ \\
Nausea & $9(14 \%)$ & $11(22 \%)$ \\
Vomiting & $5(8 \%)$ & $7(14 \%)$ \\
Pruritus & $3(4 \%)$ & $5(10 \%)$ \\
Sedation & $8(12 \%)$ & $11(17 \%)$ \\
Post-delivery hypotension & $7(11 \%)$ & $7(14 \%)$ \\
Shoulder tip pain & $2(3 \%)$ & $3(6 \%)$ \\
\hline
\end{tabular}




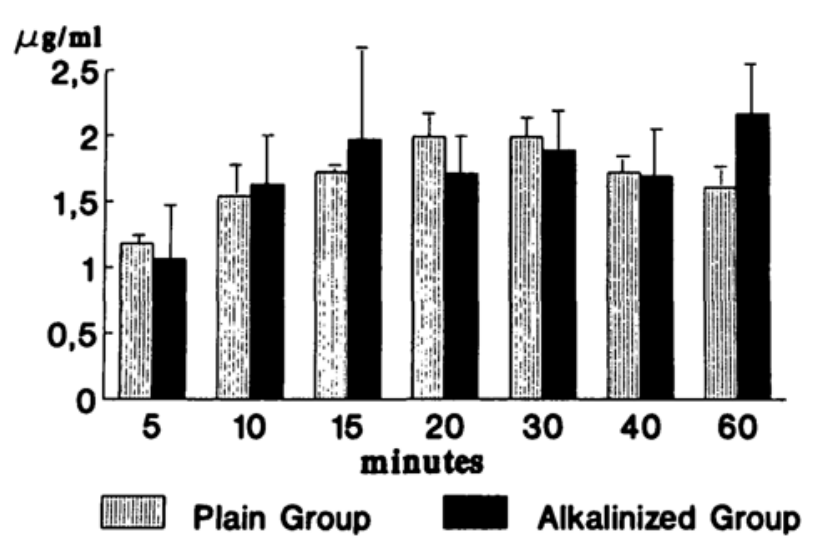

FIGURE 1 Mean (SD) maternal plasma concentrations of lidocaine.

tween the groups. Maternal plasma concentration of fentanyl at birth was greater in the alkalinized group as well as the umbilical artery concentration and the umbilical artery to umbilical vein ratio $(P<0.001)$ (Table $\mathrm{V}$ and Figure 2).

At postoperative interview, all mothers who required supplemental analgesics and sedatives during surgery were satisfied with the anaesthesia they had received. However, two of them, who received intravenous diazepam, had amnesia of the delivery of the infant immediately after surgery, in the recovery room.

\section{Discussion}

In order to increase the amount of lipid-soluble base needed to cross the nerve membrane, the base form of the local anaesthetic solution may be increased by adjusting the $\mathrm{pH}$ of the solution near the values of its $\mathrm{pKa}$. The $\mathrm{pKa}$ of lidocaine is 7.9 and in this study, the $\mathrm{pH}$ of the solution used was raised from 6.6 to 7.1 so that a larger amount of the un-ionized form, responsible for anaesthetic penetration, was presumably available. The addition of bicarbonate to the local anaesthetic, in order to adjust its $\mathrm{pH}$, produces not only a change in $\mathrm{pH}$, but also an increase in $\mathrm{PCO}_{2}$. Carbon dioxide very likely will also diffuse into the axon, acting as a membrane permeant acid, facilitating the formation of lidocaine in an active cationic form within the axon. "In addition, there may be a direct action of $\mathrm{CO}_{2}$ by modulating axoplasmic-free calcium and by a chemical combination with channel molecules or chemical modulating molecules. ${ }^{12}$ The amount of $\mathrm{PCO}_{2}$ developed by the addition of bicarbonate into a closed system such as the syringe was half that present in carbonated lidocaine solutions, but may have been sufficient to exert a pharmacological action."

Alkalinization of local anaesthetic solutions to speed

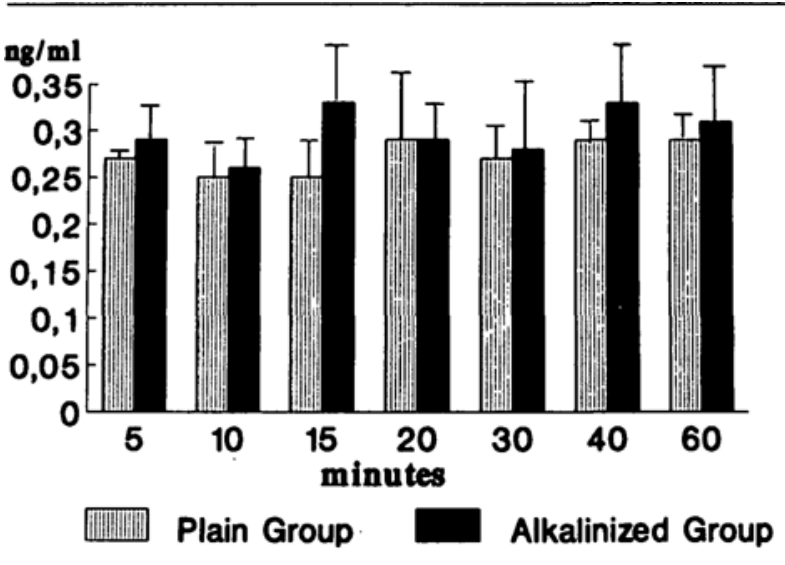

FIGURE 2 Mean (SD) maternal plasma concentrations of fentanyl.

the onset of action has been used, with varying degrees of success, by several workers. ${ }^{13-15}$ Previous studies, using a single bolus method, obtained a more rapid onset time. 8,16

Others did not find any difference in onset time using an incremental technique to deliver the local anaesthetic into the epidural space. ${ }^{17}$ We used an incremental technique and the alkalinization of lidocaine produced a small but statistically significant reduction of onset to $S_{1}$ as well as of the I-D interval, but was not associated with a reduction in onset time analgesia to $T_{4}$.

Greater incidence of maternal hypotension has been reported with alkalinized solutions when given to sitting patients with a single injection method. ${ }^{18}$ In this study the incidence of maternal hypotension was not increased, and it was comparable with that reported by others with spinal and epidural fentanyl-bupivacaine. ${ }^{3,6,19}$ This may be because the local anaesthetic solution was administered with the patient supine, with left lateral uterine displacement and by intermittent bolus injections. The incremental technique was used in this study to avoid maternal hypotension although it probably prevented us from obtaining a greater reduction of the onset time. Nevertheless, the mean onset time to $T_{4}$ was only ten minutes longer than that obtained with spinal fentanyl-bupivacaine. ${ }^{19}$

The administration of the alkalinized solution was associated with greater maternal comfort and reduced requirement for analgesics during operation, without affecting the incidence of maternal side effects and neonatal outcome. Fentanyl is reported to enhance local anaesthetic when both are administered by the epidural route. $^{3-6}$ In this study alkalinization of the local anaesthetic increased further the potency of the local anaesthetic-fentanyl solution, and reduced the incidence of intraoperative visceral pain. 
TABLE V Mean (SD)

\begin{tabular}{lcccccc}
\hline & $\begin{array}{l}U \nu \\
(n=20)\end{array}$ & $\begin{array}{l}U a \\
(n=19)\end{array}$ & $\begin{array}{l}M v \\
(n=20)\end{array}$ & $\begin{array}{l}U v / M v \\
(n=20)\end{array}$ & $\begin{array}{l}U a / U \nu \\
(n=19)\end{array}$ & $\begin{array}{l}P: D \\
(n=20)\end{array}$ \\
\hline Lidocaine & & & & & & \\
Alkalinized group & 0.98 & 0.88 & 2.19 & 0.60 & 0.95 & 0.0045 \\
& $(0.26)$ & $(0.27)$ & $(0.86)$ & $(0.56)$ & $(0.36)$ & $(0.0021)$ \\
Plain group & 1.19 & 0.99 & 1.99 & 0.57 & 0.74 & 0.0045 \\
& $(0.69)$ & $(0.86)$ & $(0.19)$ & $(0.29)$ & $(0.29)$ & $(0.0007)$ \\
Fentanyl & & & & & & \\
Alkalinized group & 0.45 & 0.45 & 0.36 & 1.28 & 0.99 & \\
& $(0.07)$ & $(0.06)$ & $(0.09)$ & $(0.34)$ & $(0.11)$ & \\
Plain group & 0.43 & 0.31 & 0.26 & 0.93 & 0.72 & \\
& $(0.05)$ & $(0.01)$ & $(0.03)$ & $(0.11)$ & $(0.30)$ & \\
$P$ & $\mathrm{NS}$ & $<0.001$ & $<0.001$ & $\mathrm{NS}$ & $<0.001$ & \\
\hline
\end{tabular}

Maternal (Mv) umbilical vein (Uv) and artery (Ua) plasma concentrations of lidocaine $\left(\mu \mathrm{g} \cdot \mathrm{L}^{-1}\right)$ and fentanyl (ng $\cdot \mathrm{ml}^{-1}$ ) at birth. Plasma concentration:dose ratio (P:D).

It is well known that overall opioid potency depends, partly, on lipid solubility, ${ }^{9,20}$ and that this may depend on $\mathrm{pH}$. The addition of an alkalinized solution to fentanyl may have increased, in vivo, its lipid solubility, and thus its penetration through the various membranes and into the spinal cord as well as its systemic adsorption. However, the increased maternal comfort in patients receiving alkalinized lidocaine may have resulted from a systemic effect of fentanyl rather than from a direct spinal effect, as suggested by the greater maternal fentanyl concentration. Normal variations in these fentanyl concentrations should also be taken into account.

The addition of bicarbonate to lidocaine did not change its placental transfer or systemic absorption, as reflected in the equal plasma concentration:dose ratios. The umbilical vein to maternal vein lidocaine ratio obtained in this study was comparable with that obtained by others with lidocaine with adrenaline 1:200,000 while the maternal vein lidocaine concentration was slightly greater, probably because of the different timing of the sampling. ${ }^{21,22}$ In addition, in this study, the mean peak maternal lidocaine concentration corresponded approximately to the drug-administration to delivery interval. In all patients plasma lidocaine concentrations were considerably smaller than those considered to be toxic. ${ }^{23}$

The umbilical fentanyl concentrations ranged from 0.20 to $0.62 \mathrm{ng} \cdot \mathrm{ml}^{-1}$, well below the concentration $(0.80$ $\mathrm{ng} \cdot \mathrm{ml}^{-1}$ ) associated with neonatal depression (low ratings for awakeness at four hours neurobehavioural examination) ${ }^{24}$ as well as the concentration associated with infant apnoea $\left(>1.0 \mathrm{ng} \cdot \mathrm{ml}^{-1}\right){ }^{25}$ The umbilical artery to umbilical vein ratios were in all cases less than one, suggesting that uptake into fetal tissues was still occurring and thus with a decreased likelihood of neonatal depres- sion. In the alkalinized group a greater umbilical artery and maternal vein fentanyl concentration and greater Ua:Uv fentanyl ratio were noted. The administration into the epidural space of the alkalinized solution immediately after fentanyl may have increased the liposolubility of fentanyl, increasing its systemic concentration in the mother and thus its placental transfer. The use of alkalinized solutions has been claimed to solve the two main disadvantages of epidural block when compared with spinal anaesthesia: slow onset time and less intense motor block. Although an onset time comparable with that obtained with spinal anaesthesia has been reported with an alkalinized solution of mepivacaine using a single bolus technique, ${ }^{16}$ the risk of a higher incidence of maternal hypotension suggests the use of an incremental dose technique, in order to reduce this side effect.

The intraoperative analgesia obtained in this study was superior to that previously described in patients receiving spinal anaesthesia, ${ }^{2,19,26,27}$ and the percentage of patients requiring additional analgesic medication was comparable with the failure rate occurring with spinal anaesthesia. ${ }^{28,29}$

In conclusion, the main positive finding of alkalinization of local anaesthetics is a decrease in latency. Although statistically significant, one must wonder if a reduction of latency by a few minutes is of any clinical importance. However, starting surgery as soon as possible may be important for Caesarean section. Fentanyl is often used as an adjunct to local anaesthetic, to improve the efficiency of epidural anaesthesia for Caesarean section. ${ }^{30}$ In our study we demonstrated that alkalinization improved further the quality, and thus the efficiency, of epidural anaesthesia performed with fentanyl and lidocaine $2 \%$ with adrenaline 1:200,000, given in incremental doses, without affecting neonatal outcome or the incidence of maternal side effects. 


\section{References}

1 Crawford JS, Davies P, Lewis $M$. Some aspects of epidural block provided for elective Caesarean section. Anaesthesia 1976, 41: 1039-46.

2 Alahuhta S, Kangas-Saarela T, Hollmen AI, Edström HH. Visceral pain during Caesarean section under spinal and epidural anaesthesia with bupivacaine. Acta Anaesthesiol Scand 1990; 34: 95-8.

3 Paech MJ, Westmore MD, Speirs HM. A double-blind comparison of epidural bupivacaine and bupivacainefentanyl for Caesarean section. Anaesth Intensive Care 1990; 18: 22-30.

4 Celleno D, Capogna $G$, Sebastiani $M$, et al. Epidural analgesia during and after Caesarean delivery. Comparison of five opioids. Reg Anesth 1991; 16: 79-83.

5 King MJ, Bowden MI, Cooper GM. Epidural fentanyl and $0.5 \%$ bupivacaine for elective Caesarean section. Anaesthesia 1990; 45: 285-8.

6 Noble DW, Morrison LM, Brockway MS, McClure JH. Adrenaline, fentanyl or adrenaline and fentanyl as adjuncts to bupivacaine for extradural anaesthesia in elective Caesarean section. Br J Anaesth 1991; 66: 645-50.

7 Tackely RM, Coe AJ. Alkalinised bupivacaine and adrenaline for epidural Caesarean section. Anaesthesia 1988; 43: 1019-21.

8 Fernando $R$, Jones $H M$. Comparison of plain and alkalinized local anaesthetic mixtures of lignocaine and bupivacaine for elective extradural Caesarean section. $\mathrm{Br} \mathbf{J}$ Anaesth 1991; 67: 699-703.

9 Kaufman JJ, Semo NM, Koski WS. Microelectrometric titration measurement of the pKa's and partition and drug distribution coefficients of narcotics and narcotic antagonists and their $\mathrm{pH}$ and temperature dependence. $\mathrm{J}$ Med Chem 1975; 18: 647-55.

10 Amiel-Tison C, Barrier G, Shnider SM, Levinson G, Hughes SC, Stefani SJ. A new neurologic and adaptive capacity scoring system for evaluating obstetric medications in full-term newborns. Anesthesiology 1982; 56: 340-50.

11 Catchlove RFH. The influence of $\mathrm{CO}_{2}$ and $\mathrm{pH}$ on local anesthetic action. J Pharmacol Exp Ther 1972; 181: 298-309.

12 Bokesch PM, Raymond SA, Strichartz GR. Dependence of lidocaine potency on $\mathrm{pH}$ and $\mathrm{PCO}_{2}$. Anesth Analg 1987; 66: 9-17.

13 McMorland GH, Douglas MJ, Axelson JE, et al. The effect of $\mathrm{pH}$ adjustment of bupivacaine on the onset and duration of epidural anaesthesia for Caesarean section. Can J Anaesth 1988; 35: 457-61.

14 Benhamou D, Labaille T, Bonhomme L, Perrachon $N$. Alkalinization of epidural $0.5 \%$ bupivacaine for Cesarean section. Reg Anesth 1989; 14: 240-43.

15 DiFazio CA, Carron H, Grosslight KR, Moscicki JC, Bolding $W R$, Johns $R A$. Comparison of $\mathrm{pH}$-adjusted li- docaine solutions for epidural anesthesia. Anesth Analg 1986; 65: 760-64.

16 Capogna $G$, Celleno D, Varrassi $G$, et al. Epidural mepivacaine for Cesarean section: effects of a $\mathrm{pH}$-adjusted solution. J Clin Anesth 1991; 3: 211-5.

17 Liepert DJ, Douglas MJ, McMorland GH, Gambling DR, Kim JHK, Ross PLE. Comparison of lidocaine $\mathrm{CO}_{2}$ two percent lidocaine hydrochloride and $\mathrm{pH}$ adjusted lidocaine hydrochloride for Caesarean section anaesthesia. Can J Anaesth 1990; 37: 333-6.

18 Parnass SM, Curran MJA, Becker GL. Incidence of hypotension associated with epidural anaesthesia using alkalinized and nonalkalinized lidocaine for Cesarean section. Anesth Analg 1987; 66: 1148-50.

19 Randalls B, Broadway JW, Browne DA, Morgan BM. Comparison of four subarachnoid solutions in a needlethrough-needle technique for elective Caesarean section. $\mathrm{Br}$ J Anaesth 1991; 66: 314-8.

20 Bentley J. Pharmacokinetic approach. In: Smith G, Covino BG (Eds.). Acute Pain, London: Butterworths, 1985 42-66.

21 Brose $W$, Cohen SE. Epidural lidocaine for Cesarean section: effect of varying epinephrine concentration. Anesthesiology 1988; 69: 936-40.

22 McLintic AJ, Danskin FH, Reid JA, Thorburn J. Effect of adrenaline on extradural anaesthesia, plasma lignocaine concentrations and the feto-placental unit during elective Caesarean section. Br J Anaesth 1991; 67: 683-9.

23 Foldes FF, Molloy $R, M c N a l l ~ P G$, Koukal $L R$. Comparison of toxicity of intravenously given local anesthetic agents in man. JAMA 1960; 172: 1493-8.

24 Eisele $J H J r$. The use of short-acting narcotics in obstetric anesthesia and the effects on the newborn. In: Estafanous FG (Ed.). Opioids in Anesthesia. London: Butterworth, 1985: 100-5.

25 Hertzka RE, Gauntlet IS, Fisher DM, Spellman MJ. Fentanyl-induced ventilatory depression: effects of age. Anesthesiology 1989; 70: 213-8.

26 Abouleish E, Rawal N, Fallon K, Hernandez D. Combined intrathecal morphine and bupivacaine for Cesarean section. Anesth Analg 1988; 67: 370-4.

27 Hunt CO, Naulty JS, Bader AM, et al. Perioperative analgesia with subarachnoid fentanyl-bupivacaine for Cesarean delivery. Anesthesiology 1989; 71: 535-40.

28 Crawford JS. There is only a limited place for spinals in obstetrics. Acta Anaesthesiol Belg 1988; 39: 181-4.

29 Lyons $G$, Macdonald $R$. 29-gauge spinal needle (letter). $\mathrm{Br}$ J Anaesth 1991; 67: 222.

30 Lussos SA, Datta S. Anesthesia for cesarean delivery Part II: Epidural anesthesia, intrathecal and epidural opioids, venous air embolism. International Journal of Obstetric Anesthesia 1992; 4: 208-21. 